\title{
Methanol Pipeline Failure in the Canyon Express Pipeline System
}

\author{
George F. Vander Voort* and Gabriel M. Lucas** \\ *Consultant-Struers Inc., 2887 N. Southern Hills Drive, Wadsworth, IL 60083 \\ **Scot Forge, 8001 Winn Road, Spring Grove, IL 60081
}

The Canyon Express Pipeline System (CEPS) was started up in November 2002 in the Gulf of Mexico, south of Louisiana. It is owned by six oil companies and collects hydrocarbons from ten wells at depths of $\sim 6100,7100$ and 7200 feet. The flow line system consists of two 12" diameter gas pipelines ("east" and "west") connected to a header system, which carries the hydrocarbons 57 miles north to a fixed platform, the Canyon Station, in about 500 feet of water. Tankers come into the Canyon Station to fill up and carry the hydrocarbons to refineries. Just west of the "east" flow line is a 2.875" diameter, X-70 line pipe that carries methanol from the station to the header where it is injected to prevent freezing of the hydrocarbons. To the left of the methanol line is a 6 " diameter umbilical line containing electrical power and hydraulic lines.

Hurricane Ivan, a category 5 hurricane, and $5^{\text {th }}$ worse in Gulf history, changed its course and struck the Ocean America semisubmersible drilling platform (searching for oil) on 15 September 2004, breaking all eight of its 3.5" diameter mooring lines. The umbilical line also stopped functioning during the storm. Four other semisubmersible drilling rigs suffered a similar fate during Ivan.

On 3 December 2004, the methanol pipe line stopped functioning, shutting down the CEPS. Subsequent searching of the sea bottom revealed a section of a broken 6X47 RRL 3.5" diameter mooring line 3.8 nautical miles west of the methanol pipe line. It was claimed that the dangling mooring line, and possibly the chain, ran over the methanol line damaging the surface, which lead to failure nearly three months later. Figure 1 shows a schematic of the claimed damage path of the Ocean America; which is also shown in Fig. 1.

Figure 2 shows a side view of the failed methanol line pipe after it was removed when the line was repaired in January 2005. The pipe, no longer circular in cross section, was oval shaped due to the expansion of the pipe. This damaged the three layers of polymer on the pipe for corrosion protection. As the pipe line was galvanically protected electrically, calcareous deposits grew on the exposed surface. This was ground off by the robot during its initial examination of the extent of the damage, producing the shinny, scratched surface, which was claimed to have been caused by the Ocean America's mooring lines, and possibly the chain, running over the pipe. Figure 3 shows two plots revealing markedly different cross-sectional hardness profiles, indicating vastly different wire drawing practices. Similar differences were seen in the thicknesses and continuity of the galvanized zinc coatings. 

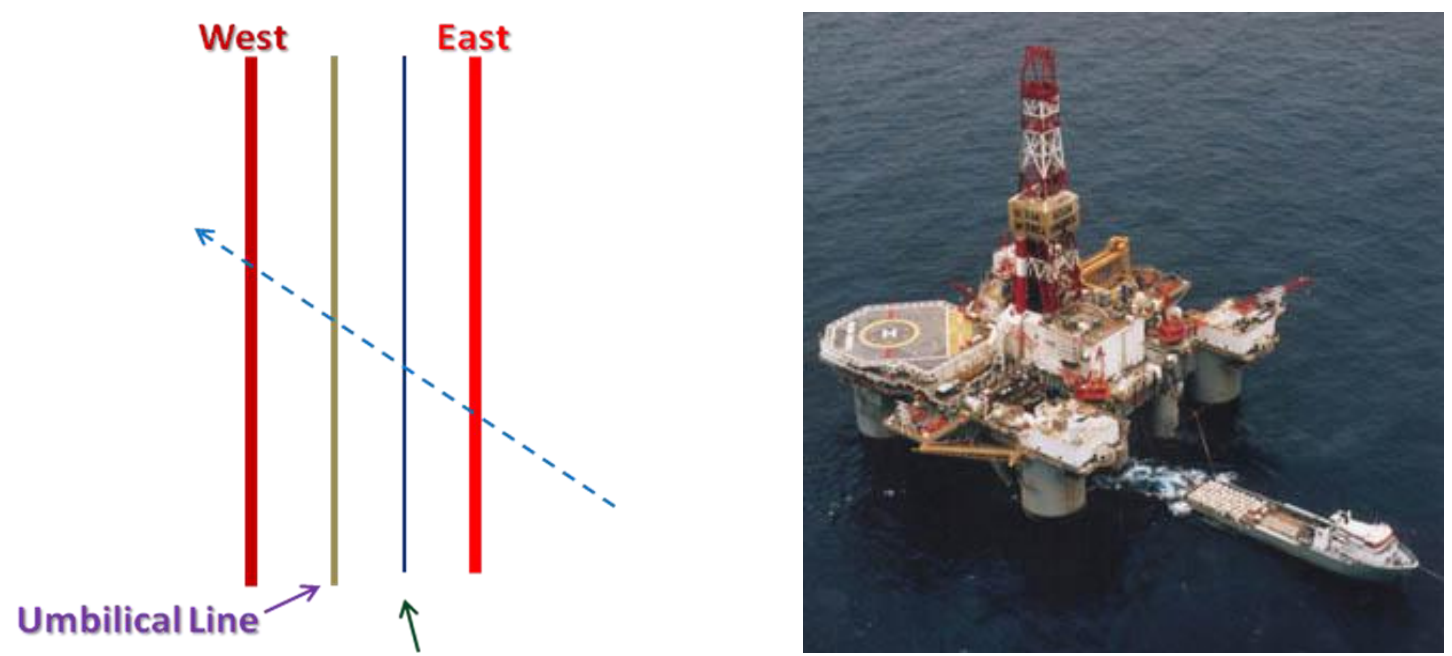

Figure 1: East and west 12" diameter steel pipelines carry hydrocarbons from the wells to the "filling station". Green arrow points to the methanol pipe line. The dotted line is the claimed route of the Ocean America (right) during Hurricane Ivan, based on biased selected damage areas.

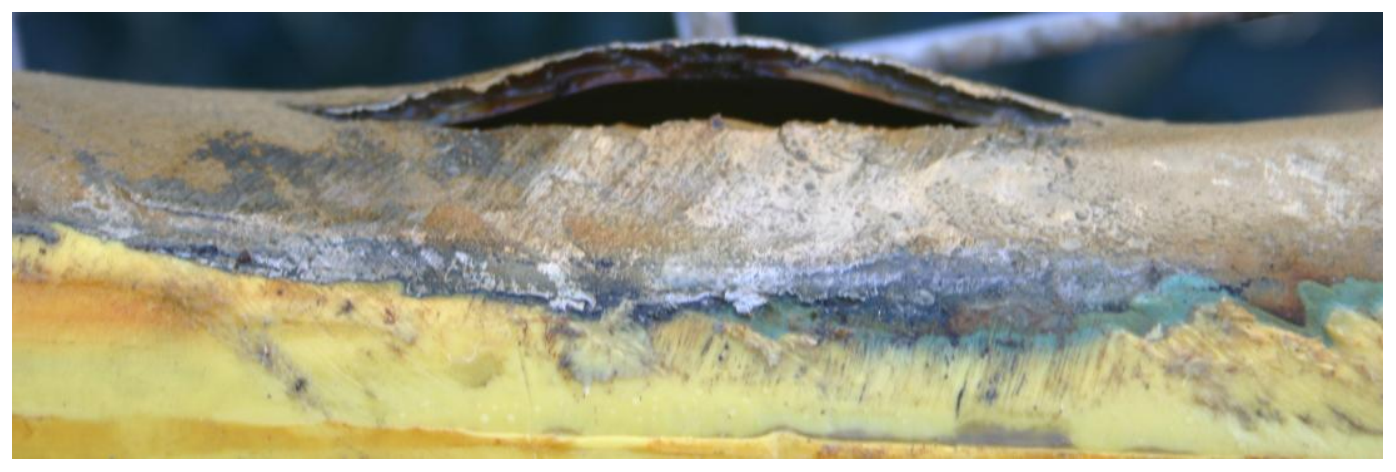

Figure 2: Side view of the cracked methanol pipe (crack is $\sim 4$ " long) after the surface was ground with a 4" diameter Weiler Power brush during the robot's initial examination in December 2004.
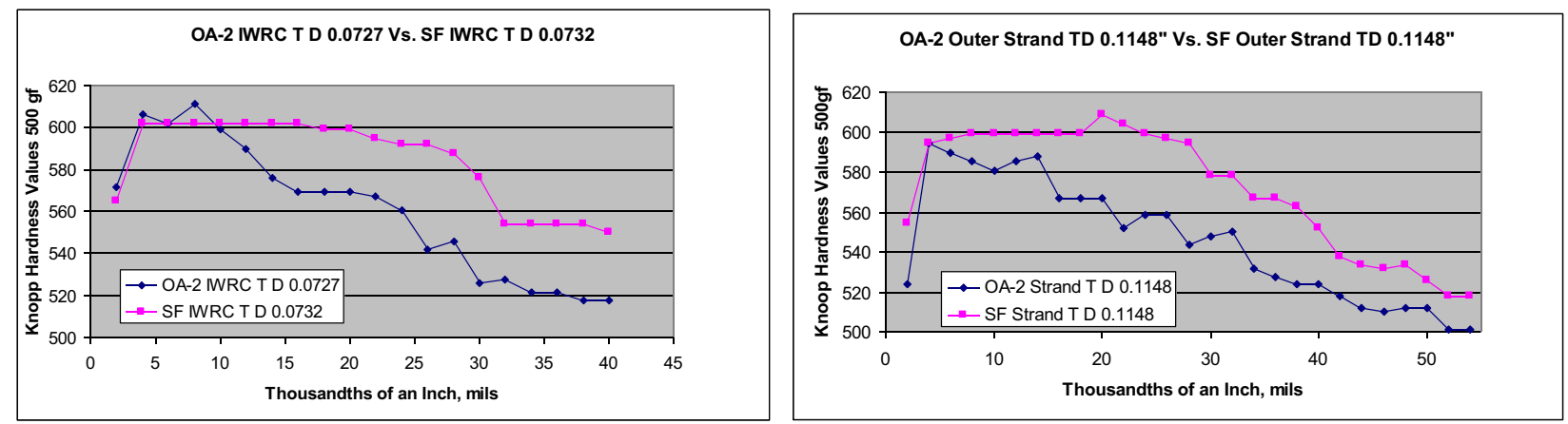

Figure 3: Two plots with markedly different wire cross-sectional hardness profiles that proved the mooring line found on the sea floor was not broken from the part still attached to the winches. 